\title{
Study of the Cultivation of Preschool Teachers
}

\author{
Bo Gan
}

\author{
Hanjiang Normal College, Shiyan Hubei, 442000, China
}

Keywords: Preschool education, Teachers, Cultivation

\begin{abstract}
Preschool teachers are the educational works in preschool education, that have significant influence on children' s behaviors and habits. As a consequence, to improve the quality of preschool education is to improve the quality of preschool teachers. At present, our country is in the crucial time of preschool education reform, the requests of the country to the preschool education teachers are, to take teacher-training as the direction of the cultivation of teachers, to exert the effect of guidance on preschool education market; to take occupation as the direction of cultivation of teachers, to adapt to the development of preschool education market. Government in the process of the cultivation of preschool teachers, should take various methods with the concept of people-oriented and with the cultivation direction of the need of the society, to cultivate high-quality and high-level preschool teachers.
\end{abstract}

\section{Introduction}

In recent years, the society is paying more and more attention on preschool education. Preschool education relates to children's habits, characters and the forming of basic senses, consequently, preschool education has a significant influence on one's life. The state council has issued relevant rules on the cultivation of preschool teachers, emphasizes the cultivation on preschool teachers, and encourages preschool teacher training colleges to actively create a scientific preschool teacher training mode, to provide excellent talents for preschool education. As a consequence, for the purpose of making preschool education reform more perfect, how to cultivate high-quality, high-level and high-capacity preschool teachers is the target of present education reform.

\section{The present cultivation on preschool teachers of our country is not enough}

It carries the important mission of future development of the country, and is the power source of the development of the country. A fine preschool education has an effective effect on student's behaviors and habits and the cultivation of healthy personality. In recent years, with the influence of the industrialization of education, our country's preschool education is no longer a public service organization, but becomes a system of being leaded by market, which makes many public kindergarten close and quite a few kindergarten teachers become unemployed. When a country is in the time of changing, if the direction of changing is wrong, then the relevant education regulations will also have deviation, which leads to serious outcome. To invest on preschool education is to invest in the future of the country, the speed and the level of the development of the country has a close connection with preschool education.

With the international society paying more and more attention on preschool education, the development of preschool education of our country has been proposed into the agenda. Our government recognizes the gap of preschool education between our country's and developed countries', has enlarged the investment on preschool education, and mobilizes all the people of the country to develop preschool education, to promote the development of preschool education. However, on the base of sufficient money, well-equiped facilities and large and powerful scale, there is still a key problem which has been solved, namely, the construction of teachers. Preschool teachers are educators in preschool education, which is the bridge between students and education, so the construction of teachers has a significant influence on the efficiency of preschool education. How to improve the quality of preschool teachers is the most important problem in the development of current preschool education. 
The cultivation of teachers is the emphasis of developing preschool education, and also the difficulty. Consequently, our government emphasizes the construction of preschool teachers. According to investigations, the ratio between kindergarten students and teachers of our country was 1;24 in 2009. From the ratio, we can know that kindergarten teachers are not enough, however, ten million more children need to access preschool education in the future five years in our country,the increase of children requires preschool teacher's number to increase. To cope with this problem, our country has issued relevant policies, such as the policy of publicly hiring preschool teachers, at the same time, primary and middle school teachers can work as kindergarten teachers after receiving training and getting the qualification. Hoping to effectively enlarge the number of preschool teachers through those measures, to improve teachers' quality.

The government also provides some methods and tactics on the construction of preschool teachers, but it needs further verification to see if it's feasible in implementation. First, we should think two important problems on preschool education: 1, preschool education is more like primary school having become the general situation of present preschool education,how can we avoid this phenomenon from happening? 2. The cultivation of preschool teachers can be done in a day, it requires a systemic training and a long-term knowledge accumulation, can non-professional people be competent to preschool teaching after a short-term training? Our study and discussion on this two problems are listed below.

First and foremost, to the problem of preschool education becoming primary school education, our government emphasizes in the policy of preschool education, that should comply with the rules of development of children and the rules of preschool education, to prevent preschool education form becoming primary school education. From this we can see that the education character and the education method of preschool education is different with primary school education. Consequently, there is a distinction between the cultivation of preschool teachers and the cultivation of normal teachers. The cultivation mode of preschool teachers takes children as the starting point, to cultivate normal school student with particular goal. Thus, to cultivate teachers to know children's psychological and physical development, to better meet the requirements of preschool teachers.From this aspect, early guidance is better than later regulation in preventing preschool education from becoming primary school education. In the cultivation of present preschool teachers, should distinguish preschool teachers and normal teachers, to emphasize the specialty of the preschool education, to improve the professionalism of preschool teachers. To improve the quality of preschool education, to realize that preschool teachers are not those who are not qualified to be primary school and middle school teachers, but professional talents after receiving systemic and professional training. As a consequence, in preschool education, we can blindly call on primary school and middle school teachers to join the preschool education with the slogan of preventing preschool education from becoming primary school. It will make the boundary line between preschool teachers and primary school and middle school teachers become unclear, which makes preschool education becoming primary school education can't be prevented effectively.

Secondly, to the problem of non-professional staff starting working as a preschool teacher after receiving a short-term training. We should clearly realize that cultivation of professional preschool teachers can not be done in a day. The cultivation of a professional worker includes professional knowledge, quality and the cultivation on occupational value and occupational habit, especially to teaching which is a very special career, which needs systemic training and long-term knowledge accumulation. The process of teaching and educating people is complicated and difficult. A teacher should not only help students improve relevant abilities and master knowledge, but also should responsible, to influence students with his own habits, personality and the charm of character, to the model of his students. As a consequence, teachers' behaviors have a huge influence on students. Especially in the phase of preschool education, children are in the period of recognizing the world and emotional experiencing, they do not have the abilities of analyzing and understanding, the process of education is mainly through observation, imitation and teacher's guidance, which makes the importance of teachers even more prominent. Thus we can see that the quality of preschool teachers affects students greatly, which concerns the future development of the country, so the requirements 
on preschool teachers' quality are much higher than that on primary school and middle school teachers. To the cultivation on preschool teachers should not blindly stress the quantity of teachers, but also emphasizes on the quality of teachers. Attention should be given to teachers' personal development in the cultivation of preschool teachers. The method and quality of cultivation can not neglected because of the lack of preschool teachers. If the cultivation on teachers is just the training of teaching techniques, to train preschool teachers in short period of time, then the cultivation on teachers can not be effectively carried out. We should rationally look at the problem of the cultivation on preschool teachers, in the cultivation and election of teachers, enthusiasm is not only the requirement, but we should cultivate preschool teachers that have professional knowledge, understand the trend of children's development and can really help children's growth. Preschool education can never lower its requirements on preschool educators just because of the lack of teachers, but should scientifically and reasonably select teachers for the specialty of preschool education.

\section{The cultivation direction of preschool teachers and the requirements}

The direction of the cultivation of preschool teachers is the base of preschool education. With the reform of education, for regulating the evaluation on the teaching qualification of our country, our country has issued many regulations in recent years. Consequently, in the process of the cultivation on preschool teachers, we should know the character, the goal and the level of cultivation. In the process of preschool teachers' cultivation, we should be perfectly aware of two questions: one, what is the standard of teachers' cultivation? The other one, who are the objects of teachers' cultivation?

To the first question, the standard of the cultivation of teachers, concerns the orientation of the cultivation of preschool teachers, in another word, it is to be aware of the orientation of the cultivation of preschool teachers, either teaching-oriented or occupation-oriented. Universities and college that are responsible to cultivate preschool teachers should not only take the demands of the society on talents as the educational guidance, but also insist on the people first education concept, it makes the cultivation of preschool education not only cultivate people particularly to meet the demands of the society, to adapt to the demand of the market, at the same time, should value people's development. In the process of the cultivation of preschool teachers, we should be perfectly aware the specialty of teacher, the essence of education is a king of skill, as a consequence, the cultivation to teachers can't be considered as the cultivation on professional workers, which only stresses on the improvement of skill, but should treat the education to teachers as the progress of growth, to take teaching as the core of the cultivation of teachers.

To the second question, the objects of cultivating teachers. Teachers should first be clearly aware of that the object is not substance, but a group of lives that have thoughts, opinions and emotion. As a consequence, the cultivation of preschool teachers is not skill training, that can not take skill as the orientation of the cultivation of teachers. Attention should be given to the relation between the demands of educational market and the education targets. Any business that is related to people education can not be demonstrated only in the form of skill, in the process of education, "growing people" should always be the core of education. Teachers are called the engineers of human beings' soul, it is because they are in the career relevant to human beings' soul. In the process of normal school cultivating, first the cultivation of character should be in the first place, then the cultivation of knowledge and the cultivation of skill. However, education is a process of practice, a teacher's character and skill is reflected in the educational process of observation and guidance. As a consequence, the cultivation and development relates to professional skill and practice. Thus, to take teaching as the first thing of the cultivation of preschool teachers, is a necessary requirement of the cultivation of preschool education.

\section{The guiding thoughts of preschool education}

The united nations educational scientific and cultural organization points out on the conference of the world child care and education, that it is not correct that preschool education is overly dependent on market. The investigation and evaluation of the united nations educational scientific and cultural 
organization finds out, preschool education overly depend on private education,, in the overly market-oriented countries, the relatively poor families have to choose the kindergarten that are low price and not assured in teaching quality for their children, which results in the children of poor families can not access to effective education and finally influences children's development. According to the investigation of the united nations educational scientific and cultural organization, we can find out that market-oriented preschool education is putting the cultivation of teachers on skill, this eventually leads to teachers having professional skills, but low quality, which lead to that the quality of preschool education can not be improved, children's development is also influenced, and eventually influence the quality level of the entire people of the country. Consequently, in the cultivation of preschool teachers, never cultivate teachers into teaching tools which constrains the development of preschool education. The cultivation of teachers should combine teaching and occupation together, taking teaching as the guidance, and taking occupation as the assistance. To break the boundary of them, to make teaching and occupation combine closely, to realize maximization of education.

In the cultivation of preschool teachers, we should take teachers' ethics as the emphasis of cultivation, to realize the multilevel and multidirectional cultivation mode. However, in any cultivation mode, we should be aware of one goal: to take the demand of the society as the basic goal of cultivation. To make a clear orientation: to take the requests of the development of children as the orientation of the cultivation of teachers. Only with the clear and correct cultivation goal and cultivation orientation, we can effectively accomplish the goal of cultivating preschool teachers. The cultivation on preschool teachers should take the concept of people first as its guiding thought, to take the demands of the society and children as the goal of cultivation, not only value the quantity on cultivating teachers, but also stress the quality of teachers' cultivation. To take teacher's ethics as the most important task, to take the cultivation of students' quality as the basic educational request.

\section{Conclusion}

According to the above-mentioned, in the cultivation of preschool teachers, our country doesn't have advantage. Our country has got some enlightenment in the cultivation of preschool teachers, through the learning of foreign countries' experience and many years experience and exploration. Our government has enlarged the investment on preschool teachers, and has carried forward relevant policies to support it, to encourage that the cultivation of preschool teachers should insist on the principle of people first and requires all teacher-training school to control the quality.

Teacher is a special career, that carries the important missions of cultivating talents for the nation and of improving the people's quality. As a consequence, the quality of teachers must be effectively assured. Preschool teachers are the enlightening teachers to students to engage education, that have huge influence on students' habit cultivation, personality cultivation and the future development, so the cultivation on preschool teachers should not only value the demand of the society, but also assure teachers' quality. In other word, it includes skill cultivation and teaching cultivation, and teaching cultivation is in the first place. Then we can cultivate preschool teachers that accord with the development of the society and have high quality and high level, and this kind of teacher meet the demands of children's development.

\section{References}

[1] Song ZuRong, Zhao ChunLong. Discussion On the Construction of Teachers of “double-certificate teachers” In Preschool Education Major. Teacher, 2011(35):19-20.

[2] Liu ManTang. The thinking On the Cultivation Mode of Preschool English Education. The Academic Newspaper of ShanXi Educational College 2011,27(4):61-64.

[3] Wang JianHua, Tang Min. Discussion On the Direction of Construction of Present Normal Universities and Colleges’ Preschool Education Major. Study of Preschool Education 2006(9):52-53. 
[4] Li YuShu. The Study On the Construction of Teachers' Assurance of Preschool Education Public Service --Taking HuNan Province for Example. Normal University of HuNan,2013.

[5] Zhu Tao, Fan YuanTao, Li YanYan, and so on. The Thinking On the Cultivation of Preschool Education Major Talents of Practical Universities. The Academic Newspaper of NeiJiang Normal College. 2013,28(7):108-110. 